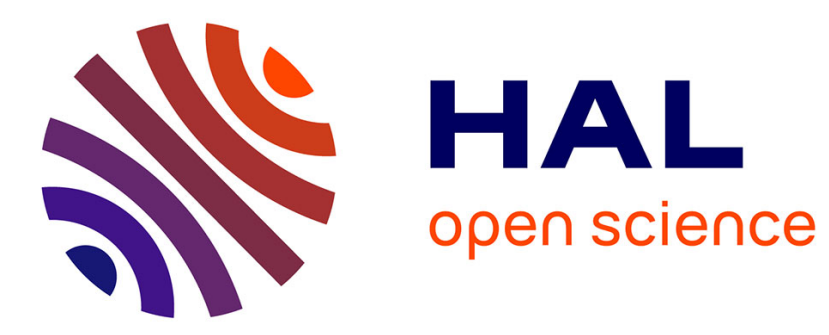

\title{
SOLUTE-ATOM SEGREGATION AND TWO-DIMENSIONAL PHASE TRANSITIONS IN STACKING FAULTS : AN ATOM-PROBE FIELD-ION MICROSCOPE STUDY
}

\author{
R. Herschitz, D. Seidman, A. Brokman
}

\section{To cite this version:}

R. Herschitz, D. Seidman, A. Brokman. SOLUTE-ATOM SEGREGATION AND TWODIMENSIONAL PHASE TRANSITIONS IN STACKING FAULTS : AN ATOM-PROBE FIELDION MICROSCOPE STUDY. Journal de Physique Colloques, 1985, 46 (C4), pp.C4-451-C4-464. 10.1051/jphyscol:1985450 . jpa-00224701

HAL Id: jpa-00224701 https://hal.science/jpa-00224701

Submitted on 1 Jan 1985

HAL is a multi-disciplinary open access archive for the deposit and dissemination of scientific research documents, whether they are published or not. The documents may come from teaching and research institutions in France or abroad, or from public or private research centers.
L'archive ouverte pluridisciplinaire HAL, est destinée au dépôt et à la diffusion de documents scientifiques de niveau recherche, publiés ou non, émanant des établissements d'enseignement et de recherche français ou étrangers, des laboratoires publics ou privés. 
JOURNAL DE PHYSIQUE

Colloque C4, supplément au $n^{\circ} 4$, Tome 46, avril 1985

page $\mathrm{C} 4-451$

SOLUTE-ATOM SEGREGATION AND TWO-DIMENSIONAL PHASE TRANSITIONS IN

STACKING FAULTS : AN ATOM-PROBE FIELD-ION MICROSCOPE STUDY

R. Herschitz, D.N. Seidman and A. Brokman ${ }^{+}$

Comell University, Department of Materials Science and the Materials Science Center, Ithaca, New York 14853, U.S.A.

The Hebrew University, Graduate School of Applied Science and Technology, Givat Ram Campus, 91904 Jemusalem, Israel

Résumé - Nous avons étudié, à l'aide d'un microscope à émissions d'ions avec sonde atomique, des effets de ségrégation pour des fautes d'empilement individuelles dans les alliages Co-0.96 at.\% $\mathrm{Nb}$ et $\mathrm{Co}-0.98$ at.\% Fe. La composition des fautes d'empilement a été mesurée dans ces alliages dans la gamme de température 450 à $575^{\circ} \mathrm{C}$. La concentration moyenne de soluté dans les fautes d'empilement décroit avec l'augmentation de température. Des petites fluctuations ( $\sim 5$ to $20 \mathrm{~A}$ de diamètre) riches en soluté, dépendant de la température, dont la composition diffère de façon significative de la composttion moyenne d'une faute, ont été observées dans le plan des fautes d'empilement. Le falt que ces fluctuations sont dépendantes de la température suggère qu'en plus de ségrégation solutée nous avons observé une phase de transition à deux dimensions dans les fautes d'empllement. Une ségrégation 1sotherme de type Fowler-Guggenheim a été dérivée ce qui explique de façon semiquantitative la dépendance de la température de la composition moyenne d'une faute.

Abstract - The atom-probe ffeld-ion microscope has been employed to study solute-atom segregation effects to individual stacking faults in Co-0.96 at.\% $\mathrm{Nb}$ and $\mathrm{Co}-0.98$ at.\% Fe alloys. The compositions of stacking faults have been measured in these alloys in the temperature range 450 to $575^{\circ} \mathrm{C}$. The mean solute concentration in the stacking faults decreases with increasing temperature. Small temperature-dependent solute-rich fluctuations ( $v$ to $20 \mathrm{~A}$ diameter), whose compositions differ significantly from the average fault compositions, have been observed in the plane of the stacking fault. The temperature dependence of these fluctuations suggests that in addition to soluteatom segregation we have observed a two-dimensional phase transition in the stacking fault. A Fowler-Guggenheim type segregation 1sotherm has been derived, which semi-quantitatively explains the temperature dependence of the mean composition of a fault.

\section{I - INTRODUCTION}

\section{I.1 - General}

The phenomenon of interfactal segregation plays an important role in determining many physical properties of materials as well as being of fundamental interest $/ 1 /$. Most of the studies of interfaclal segregation deal either with grain boundarles or free surfaces, while little attention has been given to solute segregation to stacking faults (SFs)--commonly called Suzuki segregation $/ 2,3 /$. Although there have been studies to elucidate the effects of alloying elements and temperature on SF energles in cobalt alloys $/ 4,5 /$, there have been no direct measurements of the compositions of SFs in any material by any technique. This is due to the fact that SFs are not readily accessible to analysis by conventional surface analytical tools.

In this paper we present the results of an atom-probe field-ion microscope (FIM) --hereafter called an atom probe--study of solute segregation to SFs in Co-0.96 at.\% $\mathrm{Nb}$ and Co-0.98 at.\% Fe alloys. The atom-probe allows us to determine the chemical identity of Individual atoms with a mass $(m)$ resolution of $(\Delta \mathrm{m} / \mathrm{m}) \sim 1 / 200$ 
16-9/. In addition, the atom-probe has a lateral atomic resolution for composition--in the surface of the FIM specimen--of a few angstroms. The depth resolution, for chemistry, is equal to the interplanar spacing of the crystallographic region analyzed. Therefore $1 t$ is an fdeal tool for studying segregation.

We have determined the temperature dependence of the solute concentration in SFs in single phase $\mathrm{Co}(\mathrm{Nb})$ and $\mathrm{Co}(\mathrm{Fe})$ alloys and analyzed the thermodynamics of segregation in the light of the observations reported. This is the first time that the composition of individual SFs has ever been directly measured. These measurements show that the local concentration of solute atoms is extremely high and that solute-solvent atom Interactions in and out of the plane of the SF can lead to the formation of ordered phases within the SF. In particular, we show that there are strong concentration fluctuations (5 to 20 A diameter), whose compositions differ significantly from the average SF composition. This leads us to the suggestion that in addition to solute atom segregation we have evidence for a disorder-order transformation within the plane of the SF. Our preliminary results on Nb segregation in Co-0.96 at.\% $\mathrm{Nb}$ alloy were reported earlier $/ 10 /$.

\section{I.2 - Stacking Faults in Cobalt-Based Alloys}

Extensive studies of both cobalt and cobalt-based alloys abound in the literature as they exhfbit an allotropic phase transformation from the hexagonal close-packed (HCP) to the face-centered cubic (FCC) structure /11-14/. The transformation is believed to be martensitic (athermal) in character, although there is also a thermal component /12/. The similarity of the close-packed FCC and HCP structures is we11 known. The atoms in the (111) planes of the FCC structure are arranged in an hexagonal pattern just as the atoms in the (0002) planes of the HCP structure. The only difference between the two structures is the way in which the closepacked layers are stacked. In an HCP structure the atoms in the second layer are positioned above one set of hollows in the first layer and the atoms in the third layer are directly above the atoms in the first layer; the stacking sequence can be denoted as $A B A B A B$, where each letter stands for a close-packed layer. Using Frank's del-nabla notation for describing any stacking sequence $/ 15,16 /$, the HCP structure is expressed as $\triangle \nabla \triangle \nabla \Delta$. The FCC lattice has the stacking sequence $A B C A B C$ $(\Delta \Delta \Delta \Delta \Delta)$

There are three types of SFs in the HCP structure that do not disturb first and second nearest-neighbor packing. The stacking sequence for each type of SF is as follows :
(1)
$1 \Delta$ intrinsic $--A B A B$ CBA $(\triangle \nabla \Delta \Delta \nabla \Delta)$
(11i) $3 \Delta$ extrinsic - ABABCABA $(\Delta \nabla \Delta \Delta \Delta \Delta \nabla)$

It is expected that the SF energy $(\gamma)$ in an HCP structure follows the sequence $\gamma_{1 \Delta}<\gamma_{2 \Delta}<\gamma_{3 \Delta} / 17 /$. There are two determinations of the SF energy of Co. The first one is due to Ericson $/ 4 /$ and he obtained $15 \mathrm{erg} \mathrm{cm}^{-2}$ (15 $\mathrm{mJ} \mathrm{m}^{-2}$ or $5.2 \mathrm{meV}$ atom $^{-1}$ ). The second determination is due to Korner and Karnthaler /19/ and they measured $\gamma_{1 \Delta}=27 \pm 4 \mathrm{erg}^{-2}\left(27 \mathrm{~mJ} \mathrm{~m}^{-2}\right.$ or $9.2 \mathrm{meV}$ atom $\left.^{-1}\right)$.

Experimental observations also indicate the presence of both intrinsic and extrinsic SFs in Co and Co-based alloys; their relative frequency of occurrence depends on the specimen's thermal history $/ 12,14 /$. At temperatures close to the FCC HCP transformation the frequency of occurrence of $1 \Delta$ intrinsic SFs is $v_{10}$ times greater than of $2 \Delta$ intrinsic SFs and approximately the same as that of the $3 \Delta$ extrinstc SFs. It was not found possible, in the FIM images, to distinguish among the contrast effects produced by different types of $S F s$ as the differences are very subtle. Hence, we use the term SF in a global sense. The SFs we observed are a result of the wire drawing process and hence are deformation faults. 


\section{II - EXPERIMENTAL DETAILS}

Wire specimens of $\mathrm{Co}(\mathrm{Nb})$ and $\mathrm{Co}(\mathrm{Fe})$ alloys were fabricated at the General Electric Research Laboratory (Schenectady, New York). Atomic absorption spectroscopy analysis was performed on these alloys and the nominal compositions were found to be Co-0.96 \pm 0.19 at.\% $\mathrm{Nb}$ and $\mathrm{Co}-0.98 \pm 0.0 .25$ at.\% Fe. These composittons are in the primary solid solution phase fields for the annealing temperature range employed $\left(450\right.$ to $\left.575^{\circ} \mathrm{C}\right) / 19 /$.

The as-received wires were in a cold-worked state and FIM images of specimens prepared from these wires exhibited an extremely high stacking-fault density $\left(>10^{11} \mathrm{~cm}^{-2}\right)$; these $\mathrm{SFs}$ had been produced by the plastic deformation associated with the wiring drawing process. Hence, a heat treatment was developed to: (a) produce a reasonable $S F$ density--a few faults in the $\sim 10^{-10} \mathrm{~cm}^{2}$ field-of-view; and (b) produce an equilibrium concentration of solute atoms on each SF.

A detalled discussion of the thermal treatments which achieved these goals are given elsewhere $120,21 \%$. At the lowest annealing temperature $\left(450^{\circ} \mathrm{C}\right)$ the estimated root-mean-squared diffusion distance $\left[\checkmark x^{2}\right]$ was equal to one-half the dis tance between two SFs. The calculated integrated number of jumps during a quench demonstrated that an upper 1imit to the corresponding value of $\sqrt{ } x^{2}$ is $<1 \mathrm{~A} / 21 /$; therefore, no redistribution of solute atoms occurred during the quench.

The specimens were not in a global thermodynamic equilibrium state, as we were unable to obtain HCP $\overline{\text { SFS }}$ in an FCC matrix for the annealing times employed. That 1s, we have studied solute atom segregation effects to FCC SFs in an HCP matrix. However, simple diffusion calculations /21/ Indicated that the SFs were probably

in local thermodynamic equilibrium. The values of $\sqrt{x^{2}}$ were large enough for the SFs to have come into thermodynamic equilibrlum with the volume surrounding them; i.e., with their solute reservoirs. In the case of the Co-0.98 at.\% $\mathrm{Fe}$ specimen annealed at $450^{\circ} \mathrm{C}$ this may not be correct.

\section{III - PRINCIPLES OF THE EXPERIMENT}

\section{III.1 - Contrast Effects Caused By Stacking Faults}

The first-order contrast effects caused by SFs in FIM images can be understood using purely geometrical considerations. A schematic diagram of the region surrounding a pole of an FIM specimen from a perfect crystal is shown in Fig. 1a. Th1s region conforms to a smoothly curved surface. The diameters of the consecutive crystal planes constituting this region are limited by this surface. The pole is characterized by a unit normal $\mathrm{n}$. For the close-packed planes only the atoms at the plane ledges protrude enough to give rise to an Image, therefore the projected image of this region consists of a series of concentric circles as shown in Fig. 1b.

A schematic diagram of an FIM spectmen which contains a single SF is shown in Figs. lc and 1d. Figure lc is a section through a pole of an FIM specimen, while Fig. Id shows the contrast effect expected in the FIM Image due to the presence of a SF. The displacement of the SF plane is characterized by the shear vector $(\vec{R})$.

The magnitude of $|\vec{R}|$ is the same everywhere on the surface of the SF. The intersection of the SF with the surface of the tIp produces an atomic step. The vertical height of this step is given by the dot product of $\vec{R}$ and $n$ graphic plane which the SF intersects, that is

$$
\vec{R} \cdot \vec{n}=\mathrm{qd}_{\mathrm{HKII}}
$$




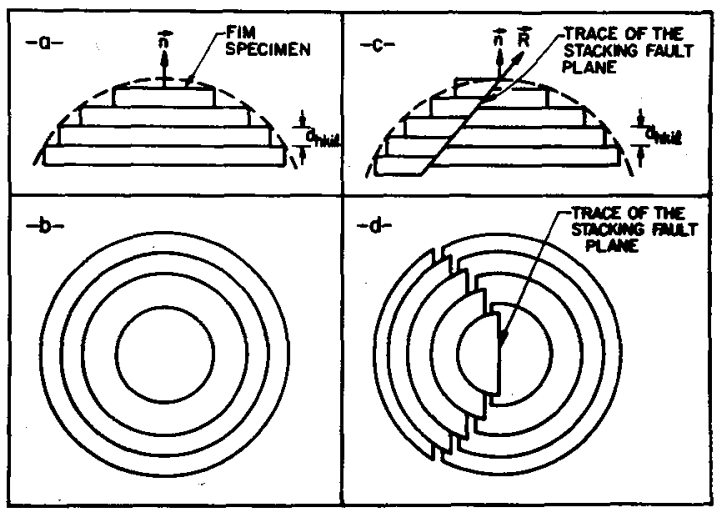

Fig. 1 - (a) A cross-sectional view of a single pole on the surface of a perfect FIM tip which is characterized by a unit normal n; (b) A projected FIM image of the pole shown in Fig. la; (c) A cross-sectional view of a single pole on the surface of an FIM tip which is intersected by a SF. An atomic step is formed on the surface as a result of the presence of the $\mathrm{SF}$; and (d) Contrast effects produced in the FIM Image by a SF when it intersects the surface of the tip.

where $\mathrm{q}=\mathrm{HU}+\mathrm{KV}+\mathrm{LW}$ and $\mathrm{d}_{\mathrm{HKIL}}$ is the interplanar spacing of a plane which the SF Intersects; (HKL) and [UVW] are the Miller Indices of the plane and a direction in a three-axis hexagonal system.

Since $U, V$ and $W$ are not necessarily integers, the quantity $q$ need not be an integer. If the vertical height of an atomic step is equal to a non-integral multiple of $d_{H K 1 L}$ then it is readily discernible in the FIM image--the planes have a horseshoe-11ke appearance. The SF is invistble when the vertical height of a step is equal to an integral multiple of $\mathrm{d}_{\mathrm{HKIL}} \cdot$ When a SF is inclined to the tip axis

its trace shifts during the field-evaporation process. Whereas when a SF is perpendfcular to the tip axis its trace is always a circle that is concentric with this axis.

\section{2 - Atom-Probe FIM Analyses of Stacking Faults}

A schematic diagram 1llustrating the basic Ideas involved in chemically analyzing a SF by the atom probe is shown in Figs. 2a and 2b. A SF, which is parallel to the axis of the tip, is shown with a number of solute atoms residing in its plane. The specimen was rotated, employing the goniometer stage, In such a way that the center of the probe hole in the Image intensification system was aligned over the SF. Each atomic plane was dissected by the application of a series of field-evaporation pulses. Typically $5 \times 10^{3}$ pulses were employed to evaporate a

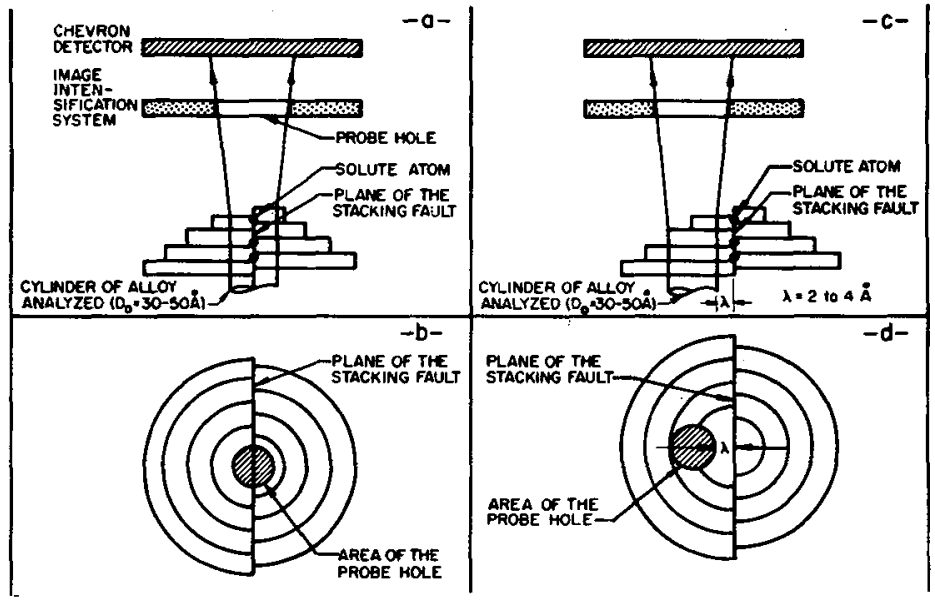

Fig. 2 - (a) \& (b) Schematic diagram illustrating the basic ideas involved in analyzing a stack1ng SF by atom-probe fleld-ion microscopy; and (c) \& (d) Schemat1c diagram illustrating the basic Ideas involved in analyzing a cylinder of alloy which is $\lambda$ A away from the $\mathrm{SF}$. 
plane containing approximately 100 atoms. The field evaporated lons which had trajectories that took them through the probe hole, in the image intensification system, were focused onto the Chevron detector with the aid of an Einzel lens. The distance of the Image intensification system from the FIM tip ( $\delta$ ) was adjusted so that the diameter of the cylinder analyzed $\left(D_{a}\right)$ was $\sim 30-50 \mathrm{~A}$. The mass-tocharge ratios of all the atoms--both $\mathrm{Co}_{0}$ and $\mathrm{Nb}$, or $\mathrm{Co}_{0}$ and Fe--in this cylinder were determined by the atom-probe technique $/ 22 /$.

To obtain the composition of the analyzed cylinder of alloy the cumulative number of $\mathrm{Nb}$ or Fe events is plotted versus the cumulative number of either $\mathrm{Nb}$ plus Co or Fe plus Co events--such a plot is called an integral profile. The average slope of this plot corresponds to the average solute composition $\left\langle c_{s}^{f}\right\rangle_{u}$ of the volume analyzed, where the superscript and subscript $f$ and $s$ stand for $S F$ and solute species ( $\mathrm{Nb}$ or $\mathrm{Fe}$ ), respectively, and the subscript $\mathrm{u}$ on the bracket means an uncorrected value. The value of $\left\langle c_{s}^{f}\right\rangle$ is a lower limit to the actual solute concentration in the SF $\left\langle c_{s}^{f}\right\rangle^{*}$. Each value of $\left\langle c_{s}\right\rangle_{u}$ must be corrected for the matrix's contribution, since the integral profile integrates over the solute-atom segregation profile assoclated with each SF and the solute-atom concentration of the matrix $/ 10,20,21 \%$. In order to determine the solute composition in a region adjacent to a SF the FIM tip was rotated in such a way that the edge of the analyzed cylinder was at a small distance $\lambda$ (A) away from the fault--see the schematic diagrams shown in Figs. 2c and 2d.

The basic limitation on the value of $\mathrm{D}_{\mathrm{a}}$ is due to the fact that the acceptance angle of the probe hole is determined by the physical dimensions of the atom probe. It has been shown by Macrander et al. /23/ that the number of lons detected during the atom-probe analysis is Inversely proportional to $\delta^{2}$; therefore, even though $D_{a}$ is smaller at larger values of $\delta$, the statistics of the atom-byatom dissection are poorer.

\section{IV - EXPERTMENTAL RESULTS}

IV. 1 - Fle1d-Ion Microscopy of Co-0.96 at.\% Nb and Co-0.98 at.\% Fe Alloys

A typical FIM image obtained from the as-received wires, which were in a coldworked state, is shown in Fig. 3. This micrograph was recorded at a specimen temperature equal to $45 \mathrm{k}$, employing neon as an imaging gas $\left(4 \times 10^{-5}\right.$ Torr gauge pressure). The density of SFs, which are identifled from the horse-shoe like contrast effect, is extremely high $\left(>10^{11} \mathrm{~cm}^{-2}\right)$. It is impossible to determine either the crystal structure or the orfentation of the specimen from the micrograph. Figure 4 exhibits an Image of the HCP phase of the Co-0.96 at.\% $\mathrm{Nb}$ alloy. This specimen had been annealed at $450^{\circ} \mathrm{C}$ for 21 days. Note the presence of at least two SFs in the field-of-view, which are separated by a distance of about $20 \mathrm{~A}$. The characteristic horse-shoe Iike contrast effect is clearly visible in the (01 $\overline{1} 0)$ plane. The SFs are FCC in an HCP matrix and Ife on a (111) plane--(0002) plane of the HCP matrix.

The FIM images show no evidence of precipttation on the SFs. However, there is "bright spot" decoration of some of the SFs. These "bright spots" may be interpreted as niobium atoms, but SFs in pure cobalt also exhibit this same "bright spot" decoration effect. Therefore, it is extremely dangerous to determine chemistry based solely on the presence of "bright spots" $/ 24 \%$. It is noted that even though the composition measured, with the atom probe, for different SFs is approximately the same, we found that some SFs were decorated with a large number of "bright spots" along their traces, while others were not decorated at all. This observation indicates that the mechanism for imaging solute atoms on SFs is a function of the crystallographic plane(s) which the SF intersects. 


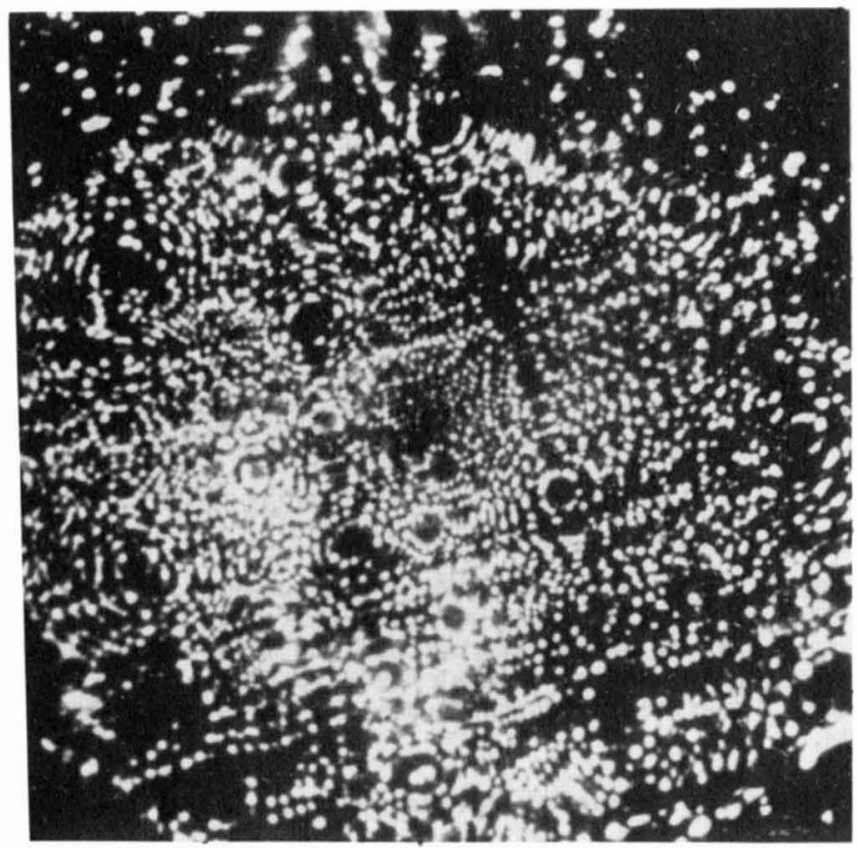

F1g. 3 - An FIM micrograph of an as-received $\mathrm{Co}-0.96$ at.\% $\mathrm{Nb}$ alloy. Note that the density of SFs, which are identified from the horse-shoe like contrast effect, is extremely high $\left(>10^{11} \mathrm{~cm}^{-2}\right)$ in this spectmen.

IV. 2 - Atom-Probe FIM Results On Solute-Atom Segregation to Stacking Faults

IV.2.1 - The Co-0.96 at.\% Nb Alloy

The $\mathrm{Nb}$ concentration was measured for specimens annealed at 450,525, and $575^{\circ} \mathrm{C}$. Also the $\mathrm{Nb}$ composition was determined in a region adjacent to SFs $(\lambda=3$ to $4 \mathrm{~A})$ --see Figs. 2c and $2 d--a s$ well as in a region far away ( 150 A) from faults. The main results for the Co- 0.96 at.\% $\mathrm{Nb}$ alloy are as follows:

(a) Very strong solute-atom segregation effects to individual SFs were observed. After due correction for the matrix contribution to the measured composition, the $\mathrm{Nb}$ concentrations in the SFs are greater than the bulk compositions by factors of 30,12 and 7 at annealing temperatures $\left(T_{a}\right)$ of 450,525 and $575^{\circ} \mathrm{C}$.

(b) The $\mathrm{Nb}$ concentration in a cylinder of alloy immediately adjacent to the SFs$--\lambda=3$ or $4 \mathrm{~A}--$ is equal to $0.91 \pm 0.17$ and $0.90 \pm 0.15$ at.\% $\mathrm{Nb}$ for specimens equilibrated at $T_{F}=575$ and $525^{\circ} \mathrm{C}$, respectlvely. These values of the $\mathrm{Nb}$ concentrations arề in good agreement with the bulk value $\left(\left\langle\mathrm{c}_{\mathrm{Nb}}\right\rangle\right)$. This indicates that the $\mathrm{Nb}$ concentration profile falls off very quickly with distance--within less than $4 \mathrm{~A}$ from the plane of the SF the $\mathrm{Nb}$ concentration is equal to $\left\langle\mathrm{c}_{\mathrm{Nb}}>\right.$.

(c) Local solute composition fluctuations were observed in the integral profiles at $\mathrm{T}_{\mathrm{a}}=525$ and $575^{\circ} \mathrm{C}$. These fluctuations are due to solute-rich regions ( 5-20A diameter) in the plane of the SF, whose concentrations differ significantly from the average SF composition. For this alloy the corrected composition of these fluctuations approaches that of a two-dimensional ordered phase. The corrected composition of the SFs at $450^{\circ} \mathrm{C}$ is close to that of $\mathrm{Co}_{2} \mathrm{Nb}$. Thts latter observation--in conjunction with the temperature dependence of the fluctuations--suggests that in addition to solute-atom segregation, we also have evidence for an unsaturated (disorder)-saturated (order) transformation within the plane of the SF. 


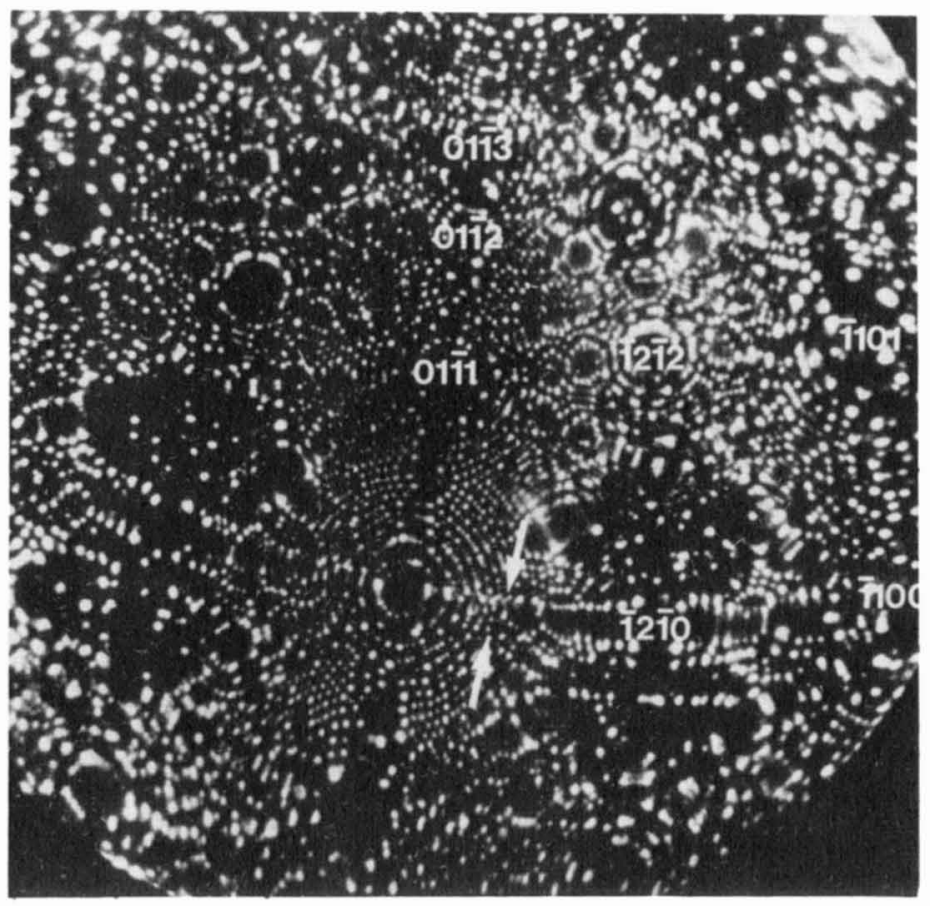

Fig. 4. - An FIM micrograph of a [01'11]-oriented crystal of the HCP phase of a Co-0.96 at.\% Nb alloy. The specimen was annealed at $\mathrm{T}=450^{\circ} \mathrm{C}$ for $2 \mathrm{I}$ days. Arrows point to two SFs in the fleld-of-view. The characteristic horseshoe like contrast effect is clearly vistble.

Figure 5 illustrates the main results obtained for a SF (SF7) in a specimen which had been equilibrated at $\mathrm{T}_{\mathrm{a}}=575^{\circ} \mathrm{C}$ for two days. The value of $\left\langle\mathrm{c}_{\mathrm{Nb}}^{\mathrm{f}}\right\rangle_{\mathrm{u}}$ is $1.34 \pm$ 0.20 at.\% $\mathrm{Nb}-$-see integral profile number 1- and the value for the corrected solute concentation $\left(\left\langle\mathrm{c}_{\mathrm{Nb}}^{\mathrm{f}}\right\rangle\right.$ ) is equal to $7.3 \pm 0.2$ at.\% $\mathrm{Nb} / 10,20,21 /$. This proflle also contalns local solute fluctuations whose values of the uncorrected local solute concentration $\left(\left\langle\mathrm{c}_{\mathrm{Nb}}^{f}\right\rangle_{\mathrm{u}, \mathrm{is}}\right)$ are equal to $2.19 \pm 0.61$ and $2.64 \pm 0.61 \mathrm{at} . \% \mathrm{Nb}$.

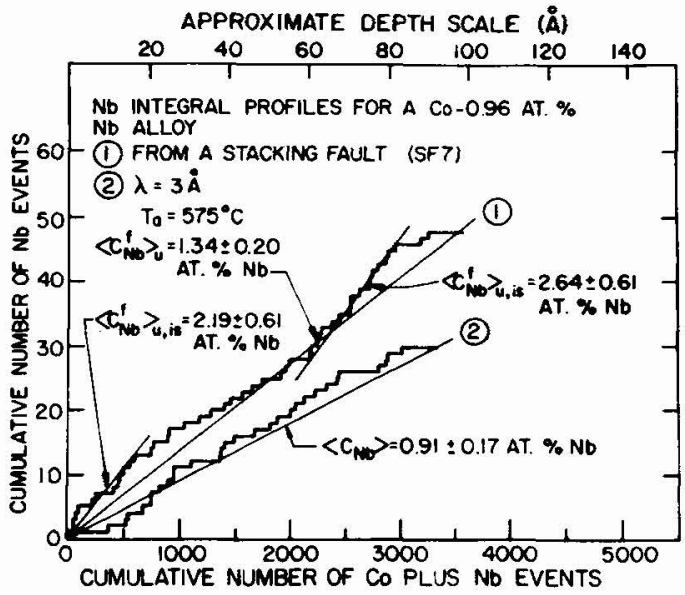

Fig. 5 - The $\mathrm{Nb}$ integral profiles for: (1) a cylinder of alloy which contained a $\mathrm{SF}$ (SF7); and (2) a region $3 \mathrm{~A}$ away from a SF (SF7) - $\left\langle\mathrm{c}_{\mathrm{Nb}}^{\mathrm{f}}\right\rangle_{\mathrm{u}}=1.34 \pm$ 0.20 at. $\% \mathrm{Nb}$ and $\left\langle\mathrm{C}_{\mathrm{Nb}}\right\rangle=0.91 \pm$ $0.17 \mathrm{at} . \% \mathrm{Nb}$. Note the presence of local solute fluctuations in

(1); $\left\langle c_{\mathrm{Nb}}^{\mathrm{f}}\right\rangle_{\mathrm{u}, \text { is }}=2.19 \pm 0.61$

at.\% $\mathrm{Nb}$. This specimen had been annealed at $\mathrm{T}_{\mathrm{a}}=575^{\circ} \mathrm{C}$ for 14 days. 
The corrected $\mathrm{Nb}$ concentrations $\left(\left\langle\mathrm{c}_{\mathrm{Nb}}^{\mathrm{f}}\right\rangle_{i s}^{*}\right)$ assoclated with these fluctuations are in the ranges $19.6 \pm 0.8$ to $46.5 \pm 1.7 \mathrm{at} . \% \mathrm{Nb}$ and $26.0 \pm 1.0$ to $50.9 \pm 2.0$ at.\% $\mathrm{Nb}$. Note that the dfameter (l) of these solute fluctuations is $\sim 20 \mathrm{~A}$; the depth scale is given on the top of the figure. Each value of $\left\langle\mathrm{c}_{s}\right\rangle_{\mathrm{u}}$, is was also corrected for the matrix's contribution. The lower 1 imtt to $\left\langle\mathrm{c}_{\mathrm{Nb}}^{\mathrm{f}}\right\rangle *$ was calculated under the assumption that the fluctuation was a rectangularly-shaped region with the dimensions $\ell \times D_{a}$, where $l$ is the measured dimension parallel to the probing direction. The upper IImit was calculated on the basis of a square-shaped fluctuation with dimensions $\ell \times \ell / 21 /$. In /21/ we show quantitatively, using a statistical theory of fluctuations, that the probabllity of the occurrence of such large $\mathrm{Nb}$ fluctuations in a random solfd-solution is nil. The integral profile labeled number two in FIg. 5 was recorded at $\lambda=3 \mathrm{~A}-$-see FIgs. $2 \mathrm{c}$ and $2 \mathrm{~d}$--and its slope corresponds to $\left\langle\mathrm{C}_{\mathrm{Nb}}\right\rangle=0.91 \pm 0.17$ at.\% $\mathrm{Nb}$. This concentration is essentially

the nominal concentration. These two integral profiles are used to prove that the $\mathrm{Nb}$ concentration falls to the matrix value within $<4$ A from the plane of the $S F$.

\section{2.2 - The Co-0.98 at.\% Fe Alloy}

The Fe concentration in the SFs was measured for specimens which had been equilibrated at 450,500 and $575^{\circ} \mathrm{C}$. Also the Fe concentration in a region adjacent to the SFs ( $\lambda=2$ and $3 \mathrm{~A})$ was determined. The main results for the Co-0.98 at.\% Fe alloy are as follows:

(a) Very strong solute-atom segregation effects were observed. After correction for the matrix contribution to the measured Fe concentration, the corrected $\mathrm{Fe}$ concentrations in the SFs are greater than the bulk concentration by factors of 10,6 and 4 at the annealing temperatures of 450,550 and $575^{\circ} \mathrm{C}$.

(b) The Fe concentration in a cylinder of alloy immediately adjacent to SFs$--\lambda=2$ or $3 \mathrm{~A}--1 \mathrm{~s}$ equal to $0.90 \pm 0.14$ and $1.04 \pm 0.30$ at.\% Fe for specimens equilibrated at $T_{1}=500$ and $450^{\circ} \mathrm{C}$, respectively. These values of the Fe concentration are in good agreement with the bulk value $\left(\left\langle c_{\mathrm{Fe}}\right\rangle=0.98\right.$ at.\% Fe). This result Indicates that the Fe concentration falls off very quickly with distance-within less than $4 \mathrm{~A}$ from the plane of the SF the Fe concentration $1 \mathrm{~s}$ equal to $<\mathrm{Fe}^{>}$.

(c) Local solute composition fluctuations have been observed in the integral profiles for spectmens which were annealed at $\mathrm{T}_{\mathrm{a}}=500$ and $575^{\circ} \mathrm{C}$. These fluctuations are due to solute-rich regions ( 20 A diameter) in the plane of the SF, whose composition differs strongly from the average composition of the SF. These large composition fluctuations do not exist in the case of a specimen annealed at $450^{\circ} \mathrm{C}$, but only become significant at 500 and $575^{\circ} \mathrm{C}$. The corrected Fe compositions of these fluctuations is close to that of a two-dimensional ordered phase with the composition $\mathrm{Co}_{3} \mathrm{Fe}$. This observation--in conjunction with the temperature dependence of the fluctuatlons--suggests that in addition to solute-atom segregatIon, we also have evidence for an unsaturated (disorder)-saturated (order)

transformation. The corrected Fe concentration $\left(\left\langle\mathrm{c}_{\mathrm{Fe}}^{\mathrm{f}}{ }_{18}^{*}\right)\right.$ corresponding to this solute fluctuation lies in the range 22.0 to 69.2 at.\% Fe. The lower 1 imit was calculated on the basis that the shape of the fluctuation is a square whose dimensions are $\ell \times \ell--$ where $\ell$ is the measured length $(14 \mathrm{~A})$ of the fluctuation paralle1 to the probing direction. The upper limit is a generous upper bound since 1 t was calculated by taking the shape of the fluctuation to be a rectangle whose dimenstons are $\ell$ and $D_{a} / 21 /$.

Figure 6 shows Fe Integral profiles for a SF (SF9) in a specimen which had been equilibrated for 14 days at $T_{a}=500^{\circ} \mathrm{C}$. The value for $\left\langle\mathrm{c}_{\mathrm{Fe}}^{\mathrm{f}}\right\rangle_{\mathrm{u}}$ is $1.43 \pm 0.22$ at.\% 


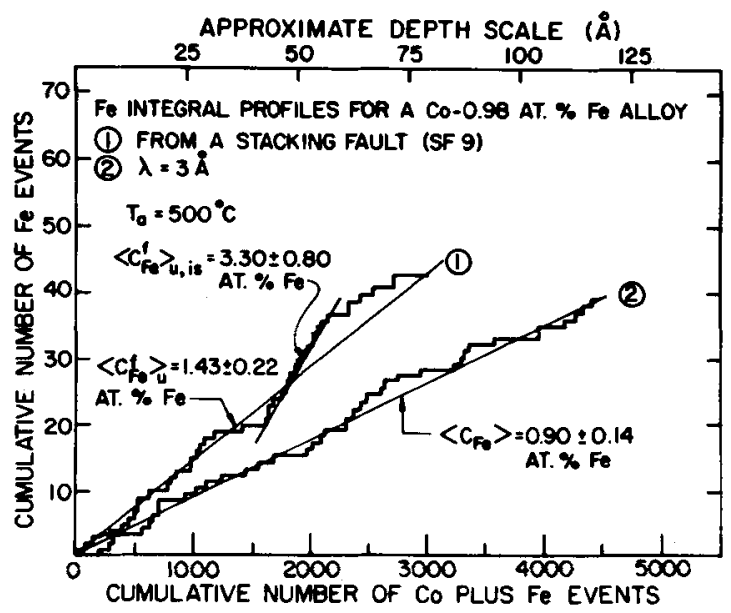

Fig. 6. - Iron integral profiles for: (1) a cylinder of alloy which contatned a SF (SF9) and (2) a region $3 \mathrm{~A}$ away from a $\mathrm{SF}$ (SF9) $\left.-<\mathrm{c}_{\mathrm{Fe}}^{\mathrm{f}}\right\rangle_{\mathrm{u}}=1.43$ \pm 0.22 at.\% $\mathrm{Fe}$ and $\left\langle\mathrm{c}_{\mathrm{Fe}}\right\rangle=$ $0.90 \pm 0.14$ at.\% Fe. Note the presence of a local solute fluctuation in (1)-$\left\langle\mathrm{c}_{\mathrm{Fe}}^{\mathrm{f}}\right\rangle_{\mathrm{u}, \text { is }}=3.30 \pm 0.80$ at.\% Fe. This specimen had been annealed at $\mathrm{T}_{a}=500^{\circ} \mathrm{C}$ for 14 days.

Fe with the SF positioned in the center of the probe hole (Figs. 2a and 2b)--see integral profile number one. The corrected value of the SF's Fe concentration $\left(\left\langle\mathrm{c}_{\mathrm{Fe}}^{\mathrm{f}}\right\rangle^{*}\right)$ is $5.8 \pm 0.2$ at.\% Fe. Integral profile number one contains a nonstatistical solute fluctuation ( $\left\langle\mathrm{c}_{\mathrm{Fe}}^{\mathrm{f}}\right\rangle$, is ) whose composition is $3.30 \pm 0.80$ at.\% $\mathrm{Fe}$. Integral profile number 2 was recorded with $\lambda=3$ A-see Figs. $2 c$ and $2 d--a n d$ its slope corresponds to $\left\langle\mathrm{c}_{\mathrm{Fe}}\right\rangle=0.90 \pm 0.14$ at.\% Fe. This concentration is only slightly less than the nominal concentration (0.98 at.\% $\mathrm{Fe})$.

\section{$V$ - DISCUSSION}

The experimental results for both the $\mathrm{Co}(\mathrm{Nb})$ and $\mathrm{Co}(\mathrm{Fe})$ alloys demonstrate that the solute atom concentration profiles associated with SFs fall to the matrix's concentration $\left(\left\langle c_{s}\right\rangle\right)$ within less than $4 \mathrm{~A}$. The spacing between the (0002) planes of HCP Co is $2.04 \mathrm{~A}$, hence the solute atom concentration in the second plane, on both sides of the SF plane, is $\left\langle c_{s}>\right.$. This result is consistent with both theoretical calculations and experimental evidence that the solute concentration profile associated with a free surface falls to $\langle c\rangle$ within a few Interplanar distances at most $/ 25-28 /$. In the case of a $3 \Delta$ extrinsic $S F$ the solute-atom segregation can be visualized as taking place substitutionally in the SF plane--see Section I.2. Thus, the solute segregation to a $3 \Delta$ extrinsic $S F$ can be purely two-dimenstonal. For a $1 \Delta$ intrinsic SF there is not a single SF plane--see Section I.2. However, there are no third nearest-nefighbor atoms in the (0002) planes immediately adjacent to the two planes associated with a $1 \Delta$ intrinsic SF. This fact in conjunction with the result that the composition of the matrix falls to $<c_{s}>$ within less than $4 \mathrm{~A}$ strongly suggests that solute segregation to the $1 \Delta$ intrinsic SF can also be two dimensional.

\section{V.1 - Fowler-Guggenheim Type Segregation Isotherm}

The experimental data indicate that at high temperatures two-dimensional regions of a phase form in the plane of the SF and that these regions grow and cover the entire plane of the $S F$ as $T_{a}$ is decreased from 575 to $450^{\circ} \mathrm{C}$. This is particularly 
clear in the case of the Co-0.96 at.\% Nb alloy. The value of $\left\langle\mathrm{c}_{\mathrm{Nb}}^{\mathrm{f}}\right\rangle^{*}$ is $\sim 31$ at.\% $\mathrm{Nb}$ at $450^{\circ} \mathrm{C}$; this corresponds to the stotchiometry $\mathrm{Co}_{2} \mathrm{Nb}$. In addition, at 525 and $575^{\circ} \mathrm{C}$ there are 5-20 A (measured dimension)--see Fig. 5--solute-rich regions with approximately this composition. In the case of the Co-0.98 at.\% Fe alloy at 500 and $575^{\circ} \mathrm{C}$ there are $\sim 20 \mathrm{~A}$ (measured dimension)--see Fig. 6 . These solute-rich islands have a composition which is consistent with the stoichlometry Co ${ }_{3}$. For both alloy systems the first-nearest neighbor interaction parameter ( $\phi$ ) is negative $/ 21,29 /$. This implies physically that the alloy wants to order (anticluster). Hence, we suggest that the saturated SF and the solute-rich islands are ordered two-dimensional phases.

In Fig. 7 we have plotted the coverage $(\theta)$ as a function of $T$ for both alloys. The saturation coverage $(\theta=1)$ corresponds to $\mathrm{Co}_{2} \mathrm{Nb}[\mathrm{Fig} .7(\mathrm{a})]$ and $\mathrm{Co}_{3} \mathrm{Fe}[\mathrm{Fig}$.

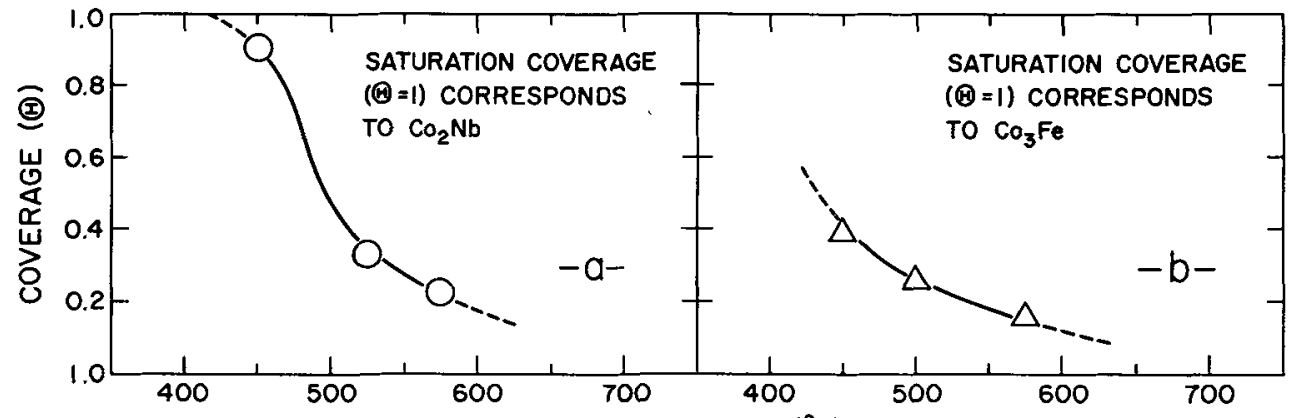

TEMPERATURE $\left({ }^{\circ} \mathrm{C}\right)$

Fig. 7. - The coverage of a SF $(\theta)$ versus temperature (T) for two cobalt alioys. The saturation coverage $(\theta=1)$ corresponds to $\mathrm{Co}_{2} \mathrm{Nb}$ (a) and $\mathrm{Co}_{3} \mathrm{Fe}$ (b).

7(b) ]. In the case of the $\mathrm{Co}(\mathrm{Fe})$ system the SFs in the specimen annealed at $\mathrm{T}_{\mathrm{a}}=$ $450^{\circ} \mathrm{C}$ may not have been in local equilibrium with their solute reservolr in spite of an annealing time of 21 days.

A statistical mechanical model was used to derive a Fowler-Guggenheim type segregation isotherm for a SF in a binary alloy, which employs a regular solution model for the primary solid solution and a "perturbed" regular solution model for the SF (Brokman and Seldman, to be published). The source of the "perturbation" is due to violations in the number of third nearest-neighbors and higher interactions out of the SF plane. The standard first nearest-neighbor regular solution mode1 can't be used for a SF, since it doesn't exhibit the necessary driving force for segregation--which has 1 ts ortgins in the third nearest neighbor and higher violations. The model assumes that the composition of the primary solid solution doesn't change during solute- atom segregation and, therefore, for a dilute alloy the quantity $\left(1-<c_{s}>\right)$ is approximately unity. The segregation isotherm equation we obtained employing the model is:

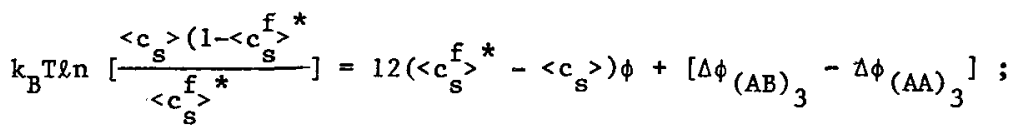

where the quantity $\phi$ is defined by

$$
\phi \equiv \phi_{\mathrm{AB}}-\left(\phi_{\mathrm{AA}}+\phi_{\mathrm{BB}}\right) / 2
$$


and the subscripts $A$ and $B$ refer to the solvent and solute specles, respectively. The $\phi_{1 j}$ 's are all taken to be negative and $\phi<0$ implies ordering (anticlustering) and $\phi>0$ signifies clustering (antiordering). The quantity $\Delta \phi(A B)_{3}$ is given by

$$
{ }^{\Delta \phi_{(\mathrm{AB})_{3}}}=\phi_{(\mathrm{AB})_{3}}^{+}-\phi(\mathrm{AB})_{3} ;
$$

where $\phi^{+}\left(\mathrm{AB}_{3}\right.$ and $\phi_{\left(\mathrm{AB}_{3}\right.}$ are the third nearest-neighbor interaction potentials in the faulted and perfect HCP lattices, respectively. The parameter $\Delta \phi(A A)_{3}$ is the SF energy in the pure HCP lattice. The segregation isotherm equation shows that initially, when the value of $\left\langle c_{s}\right\rangle^{*}$ is equal to or only slightly greater than $\left\langle c_{s}\right\rangle$, the segregation is driven by the quantity $\left[\Delta \phi(\mathrm{AB})_{3}-\Delta \phi(\mathrm{AA})_{3}\right]$ which has its physical origin in the third nearest neighbor and higher violations. The difference $\left[\Delta \phi_{(A B)_{3}}-\Delta \phi_{(A A)_{3}}\right]$ is the heat of segregation or more formally the partial atomic enthalpy of segregation $\left(\Delta \overline{\mathrm{H}}_{s, \mathrm{seg}}^{f}\right)$. When $\left\langle\mathrm{c}_{\mathrm{s}}\right\rangle^{*}$ exceeds $\left\langle c_{s}\right\rangle$ the first nearest-neighbor interactions drive the segregation process as a result of the term $12\left(\left\langle c_{s}^{f_{s}}\right\rangle^{*}-\left\langle c_{s}\right\rangle\right) \phi$. Physically $\phi$ represents the change in energy which occurs when we interchange an $A$ atom and $a$ B atom on any two sites in the crystal. It should also be noted that when $\phi$ equals zero--ideal solution behavior--then the above segregation isotherm reduces to the Langmuir-McLean segregation 1sotherm $\mid 30-37 /$.

The segregation 1sotherm was evaluated employing the following values: (a) $\phi=$ $-0.06 \mathrm{eV}$ atom $^{-1}$--this value was calculated both from heat of sublimation and surface tension data $/ 21,29 /$; (b) $\Delta \phi\left(C_{0} C_{0}\right)=9 \mathrm{meV}$ atom ${ }^{-1}$-this value is the measured SF energy /19/ in pure HCP cobalt; and (c) $\Delta \phi(\mathrm{CONb})_{3}=25 \mathrm{meV}$ atom $^{-1}-$ we were unable to find any data which predicted $\Delta \phi(\mathrm{CoNb})_{3}$, hence we used a value which is in line with that of other alloys $/ 38 /$. This set of values predicts a transition temperature of $2575^{\circ} \mathrm{C}$, which is close to the observed transition temperature.

The important point to note is that one doesn't need a large value of $\Delta \overline{\mathrm{H}}_{\mathrm{s}}^{\mathrm{f}}$, seg to obtain extensive solute-atom segregation effects, if due account is taken for all the solute-solvent interactions that occur for solute atoms in the SF, once $\left\langle c_{s}^{f}\right\rangle^{*}$ exceeds $\left\langle c_{s}\right\rangle$. Hence, relatively small negative values of $\Delta \overline{\mathrm{H}}_{s, \text { seg }}^{f}$ and $\phi$ can lead to coplous solute-atom segregation effects. If the Langmu1r-McLean segregation 1sotherm $/ 30-37 /$ is applied then the $\Delta \overline{\mathrm{H}}_{8, \mathrm{f}}^{\mathrm{f}}$, values are -0.6 and $-0.3 \mathrm{eV}$ atom $^{-1}\left(13.8\right.$ and $6.9 \mathrm{kcal} \mathrm{mol}^{-1}$ ) for the $\mathrm{Co}-0.96$ at.\% $\mathrm{Nb}$ and $\mathrm{Co}-0.98$ at. $\% \mathrm{Fe}$ alloys, respectively. These large values of $\Delta \overline{\mathrm{H}}_{\mathrm{s}, \mathrm{feg}}^{\mathrm{f}}$ are the result of the application of this 1sotherm equation to a situation where it is Inapplicable--that is, at high solute-atom concentrations in the SFs.

We now consider our observation of small two-dimensional ordered islands with the composition $\mathrm{Co}_{2} \mathrm{Nb}$ co-existing with a two-dimensional solid solution with a lower mean $\mathrm{Nb}$ concentration at 525 and $575^{\circ} \mathrm{C}$ and the observation of a saturated $\mathrm{SF}$ with the composition $\mathrm{Co}_{2} \mathrm{Nb}$ at $450^{\circ} \mathrm{C}$. To explain qualitatively these observations we 
have employed the results of the presently available theories of phase transitions in two-dimensions. The negative value of $\phi$ indicates that each co atom wants to surround Itself with $\mathrm{Nb}$ atoms or that the $\mathrm{Nb}$ atoms prefer to interact with one another via second or higher nearest neighbor sites of the stacking fault's triangular lattice. The only places for the $\mathrm{Nb}$ atoms in the $\mathrm{SF}$ are in substitutional sites within the plane of the SF. The ordered planar structure corresponds to $\mathrm{Co}_{2} \mathrm{Nb}(33.33 \mathrm{at} . \% \mathrm{Nb})$. The antiferromagnetic analogy of this two-dimensional structure 1s described by spin systems with an up spin $(\uparrow)$ on the lattice sites occupled by $\mathrm{Nb}$ atoms and a down spin $(t)$ on the lattice sites occupled by Co atoms. The ground state of the $\mathrm{Co}_{2} \mathrm{Nb}$ structure is three-fold degenerate and should belong to the universality class of the three state Potts model $/ 39 /$. With this in mind we employed the available phase diagrams for the $\sqrt{3} \times \sqrt{3}$ phase of an adsorbed rare gas layer on a graphtte surface $/ 40 /$ and scaled the temperature with the value of $\phi / 2$. These phase diagrams contain multi-critical points and an order-disorder transition which is the analog of the transition from the $\sqrt{3} \times \sqrt{3}$ superstructure to a lattice gas $/ 41,42 /$. By analogy they contain a coexistence region of ordered $\mathrm{Co}_{2} \mathrm{Nb}$ with a two-dimensional disordered solid solution of $\mathrm{Co}$ and $\mathrm{Nb}$--the latter is the analog of the $\sqrt{3} \times \sqrt{3}$ superstructure plus lattice gas coex1stence phase fleld. The latter phase field was calculated for the lattice gas system and has been observed experimentally for a krypton monolayer on a graphite surface 143/. This scaled phase diagram may explain our observation of ordered two-dimensional Islands within a two-dimensional random solid solution.

\section{ACKNOWLEDGMENTS}

This research was supported by the U.S. National Sclence Foundation through the Cornell Materials Science Center. A. Brokman was supported by the U.S.-Israel Binational Science Foundation. Additional support was recelved from the U.S. Department of Energy from the use of certain technical factlities. Prof. H. H. Johnson is thanked for kind encouragement and Prof. J. M. Blakely for useful discussions.

\section{REFERENCES}

1. W.C. Johnson and J.M. Blakely, editors, Interfacial Segregation (American Society for Metals, Metals Park, Oh1o, 1979).

2. H. Suzuki, Sci. Rep. Res. Inst. Tohoku Univ. A 4 , 452 (1952).

3. H. Suzuki, J. Phys. Soc. Japan 17, 322 (1962).

4. T. Ericson, Acta Metall. $14,85 \overline{3}$ (1966).

5. T.C. Tisone, Acta Metall. 21, 229 (1973).

6. A. Wagner, T.M. Ha11 and D. . Sefdman, Rev. Sc1. Instrum. 46, 1032 (1975).

7. T.M. Hall, A. Wagner, A.S. Berger and D.N. Seldman, Scripta Meta11. 10, 485 (1976).

8. T.M. Hall, A. Wagner, and D.N. Seldman, J. Phys. E: Sci. Instrum. 10, 884 (1977).

9. A. Wagner, T.M. Hall, and D.N. Seldman, J. Nucl. Mater. $69 \& \underline{70}, 413$ (1978).

10. R. Herschitz and D.N. Seidman, Scripta Metall. 16, 849 (1982).

11. 0.S. Edwards and H. Lipson, Proc. Roy. Soc. A $\frac{180}{180}, 268$ (1942).

12. C.R. Houska, B.L. Averbach and M. Cohen, Acta Metal1. 8,81 (1960).

13. D. Creagh, S.G. Bailey and G.Y.H. Wilson, Ph11. Mag. 32,405 (1975).

14. S. Mahajan, D. Brasen and T. Wakfyama, Metal1. Trans. A, 9A, 1817 (1978).

15. F.C. Frank, Phil. Mag. 42, 1014 (1951).

16. W.T. Read, D1slocations In Crystals (McGraw-H111, New York, 1953), p. 94.

17. J.P. Hirth and J. Lothe, Theory of Dislocations (McGraw-Hill, New York, 1968), pp. 334-336.

18. A. Korner and H.P. Karnthaler, Ph1l. Mag. A 48, 469 (1983).

19. M. Hansen and $\mathrm{K}$. Anderko, Constitution of Binary Alloys (McGraw-Hi11, New York, 1958), pp. 472, 484 . 
20. R. Herschitz and D.N. Seldman, Cornell Materials Sclence Center Report No. 4988 (1983); to appear In Acta Metall. (1985).

21. R. Herschitz and D.N. Sefdman, Cornell Materials Science Center Report No. 4989 (1983); to appear in Acta Metall. (1985).

22. R. Herschitz and D.N. Seldman, Surface Sc1. 130, 63 (1983).

23. A.T. Macrander, M. Yamamoto, D.N. Seidman and S.S. Brenner, Rev. Sict. Instrum. 54, 1073 (1983).

24. P.R. Howe11, D.E. Fleet, A. H11don and B. Ralph, J. Microscopy 107, 155 (1976).

25. S. Ono, Memoirs of the Faculty of Engineering, Kyushu Unfversity 12,1 (1950).

26. F.L. Williams and D. Nason, Surface Sc1. 45, 377 (1974).

27. Y.S. Ng and T.T. Tsong, Surface Sc1, 78, 419 (1978).

28. Y.S. Ng, T.T. Tsong and S.B. Mclane, Phys. Rev. Lett. 42, 588 (1979).

29. L. Kaufman, Calphad 1, 7 (1977).

30. J.E. Born, Acta Meta11. 11,218 (1963).

31. R. DeWitt and R.E. Howard, Acta Metall. 13, 655 (1965).

32. T. Ericson, Acta Metall. 14, 1073 (1966).

33. J.P. Hirth, Meta11. Trans. 1, 2367 (1970).

34. D. McLean, Grain Boundaries in Metals (Oxford University Press, 1957), pp. 116-149.

35. J.M. Blakely and M. Eizenberg, In The Chemical Physics of Solid Surfaces and Heterogeneous Catalysis, edited by D.A. King and D.P. Woodruff (Elsevier Scientific Publishing Company, Amsterdam, 1981), Vo1. 1, pp. 1-80.

36. R. Defay, I. Prigogine, A. Bellmans and D.H. Everett, Surface Tenston and Adsorption (Longmans, London, 1966).

37. P. Wynblatt and R.C. Ku, in Interfacial Segregation, edited by W.C. Johnson and J.M. Blakely (American Society for Metals, Metals Park, Ohfo, 1979), pp. 115-136.

38. K. Ishida, Phys. Stat. Sol, a 36, 717 (1976).

39. S. Alexander, Phys. Letts. 54A, 353 (1975).

40. H. Schick, J.S. Walker and M. Wort1s, Phys. Rev. B 16, 2205 (1977).

41. A.N. Berker, in Ordering in Two Dimensions, editor, $\bar{S} . \mathrm{R}$. Sinha

(North-Holland, Amsterdam, 1980), pp. 9-15.

42. S. Ostland and A.V. Berker, Phys. Rev. B 21, 5140 (1980).

43. D.M. Butler, J.A. Litzinger, G.A. Stewart and R.B. Griffiths, Phys. Rev. Letts. 42,1289 (1979).

\section{DISCUSSION}

J.R. Smith: How much of a perturbation of the solute distribution is due to (a) the proximity of the stacking fault to the surface or, (b) the very large fields that you apply?

D.N. Seidman: All of the specimens were annealed in the form of wires which were approximately $2 \times 10^{-3} \mathrm{~cm}$ in diameter. They were then electroetched to form the sharply pointed field-ion microscope specimens. Hence, the initial distribution of solute atoms is characteristic of the bulk. The large electric fields associated with both the imaging and evaporation fields falls off within less than $1 \mathrm{~A}$ from the surface (the screening distance). Hence, the solute atoms in the stacking fault only "feel" the electric field when they are at the surface. There is no experimental evidence that at the cryogenic temperature at which we worked ( $<45$ 
K) that the electric field gradients parallel to the surface of the FIM tip cause a redistribution of solute atoms. This point has been studied in detail by Ehrlich and co-workers (Univ. of Illinois) and Tsong and co-workers (Pennsylvania State Univ.) for the case of adatom surface diffusion. These researchers found - for this more severe case - that at cryogenic temperatures the imaging electric did not perturb the positions of adatoms. Thus, one could not expect the electric field to perturb the solutes atom distribution in the stacking fault. 